Aletria, Belo Horizonte, v. 28, n. 1, p. 83-98, 2018

(c) (1)

\title{
Mistura de gêneros, dentro e fora da literatura ${ }^{1}$
}

\section{Fusing genres, within and without literature}

\author{
Fernando Baião Viotti \\ Universidade Federal de Minas Gerais, Belo Horizonte, Minas Gerais / Brasil \\ fviotti@ufmg.br
}

Resumo: Poucas vezes uma premiação literária provocou tanto debate quanto o Nobel de Literatura concedido a Bob Dylan em 2016. A láurea trouxe para a esfera pública uma discussão em geral reservada ao ambiente acadêmico, quanto ao que se deve ou não abrigar sob a denominação de literatura. Dylan respondeu à sua maneira, manejando recursos de linguagem peculiares. Cada um dos quatro lances da sua resposta lida com elementos típicos do discurso literário: a elipse, a ironia, a representação e a heterogeneidade. Da distinção de gêneros entre poesia e canção surge um questionamento mais amplo quanto às fronteiras que separam o discurso literário dos demais. O jogo de Dylan com a linguagem expande o cruzamento de fronteiras entre os gêneros que sua obra coloca para além dela mesma, abrangendo os discursos não literários e até mesmo um determinado modo de ser.

Palavras-chave: gêneros; canção; poesia; século XX; Bob Dylan; Nobel Prize.

Abstract: Few times has a literary prize generated such controversy as the Nobel Prize of literature awarded to Bob Dylan in 2016. After the announcement, a discussion, normally kept inside the walls of universities, spread out to the public sphere, centered on which art forms should be called literature. Dylan answered on his own terms, using a peculiar range of language resources. Each of the four acts of his answer deals with elements typical of literary space, such as ellipsis, irony, representation and heterogeneity. From the main distinction between poetry and song arises a more comprehensive questioning about the boundaries that puts literary discourse apart from other kinds of discourses. Dylan's play with language expands the border crossing among genres suggested by

\footnotetext{
${ }^{1}$ Para o Emílio Maciel, com afeto e admiração.
} 
his work beyond itself, encompassing non-literary discourses and even his unique modus vivendi.

Keywords: genres; song; poetry; 20th century; Bob Dylan; Nobel Prize.

\section{Introdução}

Como se sabe, critérios de classificação apresentam enorme variação no tempo e no espaço, e muito do que a opinião unânime hoje considera literatura surgiu originalmente sob outras rubricas, ao mesmo tempo em que a crescente especialização dos saberes passou a exigir denominações mais precisas capazes de circunscrever objetos como o relato histórico ou o ensaio. Tudo muda, mas, no princípio, era a poesia. A poesia cantada, para ser mais exato, se ficarmos no âmbito da tradição ocidental e tomarmos a épica homérica como um marco fundador. Poesia cantada que, curiosamente, funda também a literatura em língua portuguesa, com as cantigas trovadorescas do século XII, eco fantasmagórico da tradição que sobrevive nos talentos individuais da canção brasileira do século XX. A secretária permanente da Academia Sueca, Sara Danius, sabia disso, e espertamente invocou Homero e Safo como avalistas ao anunciar a escolha do premiado com o Nobel de literatura em 2016:

Nós ainda lemos Homero e Safo, e eles estavam escrevendo 2500 anos atrás. Era [poesia] para ser apresentada, frequentemente com instrumentos, mas eles têm sobrevivido, e sobrevivido incrivelmente bem, na página do livro. Nós apreciamos a sua poesia, e eu penso que Bob Dylan merece ser lido como poeta. ${ }^{2}$

A despeito de seu potencial para agradar gregos e troianos a justificativa de Danius não foi suficiente para evitar a controvérsia. As

\footnotetext{
2 "We still read Homer and Sappho, and they were writing 2,500 years ago. They were meant to be performed, often together with instruments, but they have survived, and survived incredibly well, on the book page. We enjoy [their] poetry, and I think Bob Dylan deserves to be read as a poet". (GUNDERSEN. World exclusive: Bob Dylan I'll be at the Nobel Prize ceremony... if I can, tradução minha)
} 
reações se dividiram, ainda que, ao cabo, os entusiastas de Dylan pareçam ter prevalecido. ${ }^{3}$

Numa rápida síntese, podemos falar em três tipos de ressalva: a formal, a estética e a ideológica. Do ponto de vista formal, a letra de música não pode ser considerada literatura, pois é apenas uma das partes de um triângulo formado por texto, melodia e voz, em que cada lado necessita do outro para compor o objeto que é a canção. Do ponto de vista estético, ligado ao anterior, houve quem objetasse contra a qualidade de Dylan como poeta, argumentando o quanto o seu mérito como artista depende de outros atributos, como o seu carisma pessoal. Suas canções, portanto, estariam fadadas a desaparecer junto com o autor. Houve finalmente os que destacassem a impropriedade em atribuir a um produto da "indústria cultural" o estatuto de alta literatura; e, além do mais, chamando de poeta um rockstar que fatura milhões de dólares por ano! Por toda sua conotação sócio-política, e sua força de propaganda, o Nobel deveria se circunscrever a autores menos conhecidos.

Não faltaram bons argumentos na réplica a cada um desses reparos. Como já se viu, excluir da canção os seus atributos no campo da linguagem é desconhecer toda a tradição poética ocidental, em que o oral e o escrito se alternam e complementam. Os estudos sobre Dylan dentro e fora das universidades há pelo menos quatro décadas, e a admiração de escritores como Samuel Beckett, Archibald MacLeish e Allen Ginsberg são apenas algumas das chancelas de sua qualidade como poeta. Finalmente, a dificuldade em caracterizar a obra de Dylan como produto típico da cultura popular, e a recusa do artista em se submeter às regras de uniformização do mercado dão prova inequívoca da dialética a que ele submete a indústria, a mídia e até mesmo o seu público mais fiel.

Um aspecto ainda não considerado devidamente parte dessa história iniciada um ano atrás foi a maneira como o próprio Dylan reagiu ao prêmio. Claro que suas reações foram comentadas exaustivamente, mas não de maneira a captar na totalidade de suas respostas um sentido

\footnotetext{
${ }^{3}$ Interessante notar que o laureado de 2017, saudado como uma escolha "segura" após a controvérsia do ano passado, tenha citado Dylan no seu discurso de agradecimento. Vale ainda lembrar que Kazuo Ishiguro é um autor de romances, gênero que até pouco tempo permanecia muito distante de ser considerado "alta literatura". Caso houvesse um prêmio Nobel de Literatura no século XVIII, dificilmente a láurea seria concedida a um romancista.
} 
suplementar para além do que aparece na superfície do seu enunciado. Não se fez, afinal, a análise formal que sua resposta, no entanto, pede.

A resposta de Dylan é uma narrativa dramática em quatro atos, na qual se projeta o jogo entre a intenção autoral e os saltos inconscientes da linguagem (encontro que pelo menos desde Montaigne é também um tema da literatura). Sua fala é uma expansão de natureza dupla, ao fazer uso de um discurso literário que problematiza não apenas as fronteiras entre os gêneros que a premiação colocara (entre poesia e canção, oral e escrito, erudito e popular), mas a própria distinção formal entre a literatura e as demais formas de expressão enunciadas fora do seu âmbito estrito, como a entrevista ou a conversa cotidiana, alcançando até um determinado modo de ser, cuja marca indelével é uma relação sempre profunda com a linguagem.

\section{Elipse}

A primeira resposta de Dylan ao anúncio do prêmio foi o silêncio. Um silêncio ensurdecedor que provocou perplexidade e confusão. Os menos familiarizados às idiossincrasias do personagem viram na atitude uma recusa, e numa remissão à aura de rebeldia construída em torno do artista, sugeriu-se que ele não aceitaria o prêmio. Falou-se em Sartre, e de imediato Maio de 1968, os protestos contra a Guerra do Vietnã, o discurso de Martin Luther em King, em Washington, em 1963 - em que Dylan cantara "The Times They Are A-Changin"” - vieram à tona. A exemplo de Sartre em 1964, esperava-se que o "cantor de protesto", o ícone da contracultura, declarasse o seu repúdio ao establishment. "Um escritor que assume posições políticas, sociais ou literárias somente deve agir com meios que lhe são próprios, isto é, com a palavra escrita", ${ }^{4}$ diria Sartre ao justificar sua recusa. Nada mais impróprio do que atribuir a Bob Dylan tal ética da convicção. O caráter transgressor de sua arte se afirma de modo complexo e contraditório, inclusa aí a negação da própria transgressão, quando esta se converte em demanda de compromisso político ou estético. Acrescente-se sua ambivalência em face dos valores da contracultura, em especial a estética flower-power, e sua retirada para uma espécie de idílio rural, tanto no âmbito pessoal quanto artístico, a partir de 1966. Enquanto o amor livre e a música psicodélica se difundiam

\footnotetext{
${ }^{4}$ SARTRE. Carta à Academia Sueca.
} 
enormemente - não sem o auxílio do próprio Dylan -, ele mesmo se dedicava à vida marital e a criar os filhos, lançando álbuns em que a tradição country, as referências bíblicas e declarações de amor quase pastoral eram os elementos mais fortes.

Mas a tentativa de adivinhar o que Dylan poderia estar pensando sobre o assunto foi apenas uma pequena parte da avalanche de artigos e entrevistas de jornalistas e acadêmicos a respeito de Dylan e do Nobel nos dias subsequentes ao anúncio. $\mathrm{O}$ vazio que o seu silêncio projetou funcionou como estímulo para novas perguntas, especulações, tentativas de compreensão que vão desde a reflexão quanto às particularidades da experiência estética contemporânea - e ao lugar nela ocupado pela canção popular -, quanto a esclarecimentos em torno de sua natureza tríplice, em comparação ao plano textual único do poema.

Qualquer coisa que Dylan dissesse nos dias seguintes ao prêmio teria o efeito de limitar o debate, direcionando-o para o campo que o laureado elegesse como o apropriado, reduzindo uma abordagem surpreendentemente diversa e produtiva sobre a questão do gênero, à mera transcrição e comentário suplementar do ponto de vista que o principal envolvido, no entanto, se absteve de declarar. Ao invés de arbitrar a questão, Dylan deixou aberto o espaço para o contraditório; o embate livre das idéias na arena pública do qual nem sempre emerge uma palavra final.

A despeito de sua aparente simplicidade formal, "Blowin' in the Wind" opera um mecanismo semelhante. A canção é também elíptica, estruturada a partir de perguntas cujo simbolismo transcendente sugere uma explicação totalizante que na verdade não virá, senão sob a forma de uma não resposta inefável, soprando no vento. Se o poeta pôde ouvila, optou afinal por mantê-la como elipse, na qual, 55 anos depois, ainda projetamos respostas impossíveis de encontrar. Podemos continuar nos perguntando: Dylan cogitou recusar o prêmio? Sentiu-se atônito com o tamanho da honraria? Preferiu aguardar o balanço das reações (que afinal acabou por mostrar-se mais positivo que negativo)? Calculou, deliberadamente, o peso produtivo do seu silêncio, como maneira de preservar a imagem de ambiguidade que o cerca, mais uma vez evitando identificar-se a estereótipos determinados, fosse o do que se rebela, quanto o que se rende aos apelos do establishment? Não se pode saber, mas pelo menos essa última hipótese parece se comunicar ao lance seguinte de sua narrativa. 


\section{Ironia}

O silêncio contínuo não é uma elipse. Ela só pode haver como um intervalo em contraste com o que efetivamente não se cala, e, de fato, duas semanas após o anúncio do prêmio, Dylan declararia estar muito agradecido pela honra: "Se eu aceito o prêmio? É claro." Quando perguntado se iria à cerimônia, responderia que "sim, se for possível". Questionado quanto à dificuldade em se obter uma declaração sua, diria simplesmente: "Bom, eu estou bem aqui", ${ }^{5}$ como se seu número estivesse nas listas telefônicas e ele não fosse um dos mais inacessíveis artistas do show business. Sem considerar o fato de que um aceno de cabeça para o seu staff teria bastado para que uma nota à imprensa dirimisse qualquer dúvida quanto a sua posição. Mas como Dylan diria à própria Academia com duas semanas de atraso: "A notícia sobre o prêmio Nobel me deixou sem palavras". 6

De fato, quem resistiria à paronomásia? Daquilo que não se pode falar é preciso calar. Mas a máxima de Wittgenstein não faz muito sentido no caso desse artista, que sempre se deixou levar pela palavra até o limite do prolixo, ultrapassando os padrões de duração da canção popular com peças caudalosas que chegavam a mais de 10 minutos numa época em que o máximo era um terço disso, ${ }^{7}$ além de não ter se furtado a compor e lançar canções e álbuns, mesmo quando a inspiração parecia não se apresentar.

O recurso ao clichê não diminui o alcance do duplo sentido irônico. Se declarar sem palavras - ou "sem discurso", tradução literal para speechless - é se dizer atônito, chocado, ou, como pede o contexto, maravilhado. Esse sentido, entretanto, que é o consagrado pelo uso, já é o figurado, pois, ao pé da letra, a expressão significa nada mais do que "mudo". No caso de Dylan, a frase aparece como uma síntese em que não há alternância, mas uma simultaneidade em que cada um dos dois

\footnotetext{
${ }^{5}$ As primeiras declarações de Dylan sobre o Nobel estão na entrevista exclusiva concedida a Edna Gundersen, publicada no The Telegraph, em 29 de outubro de 2016. (Cf. GUNDERSEN. World exclusive: Bob Dylan - I'll be at the Nobel Prize ceremony... if I can, tradução minha)

6 "The news about the prize left me speechless". (PONTIKIS. Newsroom for the Nobel Foundation, tradução e grifo meus)

${ }^{7}$ Quando "Like a Rolling Stone" foi lançada, em 1965, as rádios costumavam executar apenas metade dos 6'05" da canção. No ano seguinte, com "Sad-eyed Lady of the Lownlands", Dylan chegaria a inimagináveis 11 minutos.
} 
sentidos está presente. Podemos dizer que ela vai além das definições clássicas de ironia, seja a inaugural, que a define como um modo de dizer algo diferente do que se pensa, seja a atualização de Aelius Donatus em sua Ars Gramatica, segundo a qual o sentido real é oposto ao sentido aparente. Para entender a ambivalência do seu alcance é forçoso lembrar que se trata da resposta a uma demanda: da mídia, do público e da Academia (talvez menos dessa última, já que o Nobel não é um prêmio que se possa "recusar", como o próprio Sartre viria a descobrir. O laureado pode optar por não ir à cerimônia, além de não receber o prêmio em dinheiro caso não ofereça a contrapartida solicitada pela Academia, mas seu nome permanecerá consignado como laureado), para que o agraciado declarasse, afinal, o que o prêmio significara para si.

Se, por um lado, "maravilhado" é uma resposta razoável, apesar de lacônica, por outro, dizer-se "mudo", justificativa que não cola para alguém loquaz como Dylan, é a recusa em ceder à demanda alheia por uma explicação, disfarçada de uma explicação que é ao mesmo tempo implausível, mas impossível de atacar, já que a ênfase no sentido figurado (maravilhado) automaticamente contém a defesa contra a insuficiência explicativa derivada da ênfase no sentido literal (mudo). O xeque-mate do enxadrista Dylan está no uso do duplo sentido da expressão, que ao mesmo tempo diz e desdiz aquilo que dele se quer ouvir. O duplo sentido contém tanto o agradecimento sincero pelo prêmio concedido, quanto o sarcasmo em face da celeuma criada em torno do seu silêncio e a recusa em se explicar.

"A ironia diz, pois, que para apreender o real do objeto visado pelo enunciado, faz-se necessário torcer a língua, produzindo enunciações que se autoanulam". ${ }^{8}$ Esse autocancelamento mútuo, entretanto, não progride ad infinitum, como aponta Safatle, encontrando seu termo no momento em que atinge o outro:

Para funcionar, a ironia deve mostrar que o sujeito nunca está lá para onde o seu dizer aponta. Dessa forma, ela pode afirmar-se não exatamente como uma operação de mascaramento, mas como uma sutil operação de revelação da inadequação entre enunciado e enunciação. Sem essa possibilidade de revelação da inadequação para o Outro, a ironia seria um mero mal-entendido. ${ }^{9}$

${ }^{8}$ SAFATLE. Cinismo e falência da crítica, p. 32.

${ }^{9}$ SAFATLE. Cinismo e falência da crítica, p. 32. 
Ou, mais precisamente no caso em questão, no momento em que atinge as duas categorias de "outro" às quais Dylan se dirige. Como na síntese de Safatle, a sutileza está no poder revelador de uma frase que, se desconsiderarmos a quem se endereça, não diria absolutamente nada. A frase não só se oferece abertamente para o Outro, como serve simultaneamente às duas classes de "Outro" que lhe demandavam uma resposta, qualquer resposta, desde que não o silêncio ensurdecedor que ele oferecera de início. A resposta maximamente sintética diante da extensão das indagações aumenta ainda mais a ironia. Em face da verborragia da mídia, Dylan se sai com o oposto perfeito de uma síntese máxima, que serve tanto como uma resposta demissionária às críticas quanto como agradecimento respeitoso pelos elogios, uma bala de prata que na sua economia de meios é simultaneamente forma e conteúdo do conceito.

\section{Representação}

Dia 10 de dezembro de 2016. Chegada a grande noite de entrega das premiações em Estocolmo, a ambivalência que Dylan expressara antes se mantém. Em carta enviada à Academia, ele se declara "extremamente honrado", mas impedido de comparecer à cerimônia devido a "outros compromissos". Excluída sua principal ocupação profissional - seu último concerto do ano ocorrera na Flórida em 23 de novembro -, restariam reuniões com empresários, gravações ou ensaios, todos facilmente remarcáveis diante da importância da ocasião. Como não se sabe quase nada de sua vida pessoal nas últimas três décadas, não é possível descartar uma eventual coincidência de datas com algum compromisso familiar, teoria que pelos mesmos motivos anteriores resta também improvável.

Ainda que o objeto de análise aqui não seja a vida empírica do artista, parece útil avançar uma hipótese sobre essa ausência, na medida em que ela se liga como causa e consequência ao momento abordado. O músico David Amram, amigo de Dylan, conta um episódio curioso ocorrido em Nova York na década de 1970:

Uma vez fomos ao Village, Sara, Dylan e eu. Estávamos olhando através de uma janela e eu disse: "Cara, eu gostaria de estar com esse pessoal" [...] Eram pessoas mais velhas, muito bem vestidas, uma bela casa, todos tomando coquetéis [...]. E Bob disse: "Eu não sei que tipo de ambiente é esse, mas uma vez que eu estiver 
lá, ele vai mudar" e riu. Então nós entramos, e todas essas pessoas bem-sucedidas, de sucesso - quando de repente viram Bob Dylan entrando - ficaram aterrorizadas como estudantes secundaristas [...], todos em silêncio. Era como se o papa tivesse chegado, eu fiquei perplexo [...]. Imagine como é ter que lidar com isso o tempo inteiro. ${ }^{10}$

Já era tempo de Bob Dylan ter se acostumado. Seu magnetismo não arrefeceu desde então, e tudo o que ele faz e diz continua atraindo enorme atenção, em alguns casos, obsessiva, o que não impediu que ele comparecesse a inúmeras cerimônias ou premiações. A Medalha da Liberdade da presidência americana (2012); a Legião da Honra do governo francês (2013); prêmios da Indústria, como o Grammy de Álbum do Ano (1998) e o Oscar de Melhor Canção (2001); títulos de Doutor Honoris Causa (Princeton, em 1972, e Universidade de St. Andrews, na Escócia, em 2004) são algumas das distinções que aceitou e recebeu pessoalmente, além de ter se apresentado para o Papa João Paulo II em 1997. Uma lista diversa que acentua o seu prestígio e enorme trânsito entre a arte alta e a cultura popular.

E que sugere que ir a Estocolomo para receber do Rei Carl XVI Gustav - que, aliás, já lhe entregara o Polar Music Prize no ano 2000 o Nobel de Literatura não seria problema para Dylan. Ocorre que, nas fotos e filmagens de qualquer uma dessas cerimônias, o desconforto de Dylan é notável; nenhuma dessas cerimônias obrigara o comparecimento a um banquete e o pronunciamento de um discurso (uma exigência do Nobel), além de não terem provocado sequer uma pequena parte da polêmica e repercussão da láurea recente. Dylan sabia que os olhos do mundo inteiro estariam constrangedoramente voltados para si, como no

10 "One time we went to the Village, [me], Sara and him and we were looking through the window and I Said, 'Man, I'm glad to be with you guys' [...] They were older people, very well dressed, beautiful town house, everybody drinking cocktails [...] And Bob said, 'I don't know what kind of a scene it is but after I've been there it's gonna change.' And he laughed. So we walked in there and all these successful, established people - when they suddenly saw Bob Dylan walk in - completely freaked out and became like gawking high-school students. [...], everybody got silent. It was like the Pope had arrived [...] it blew my mind. [...] what it must be like to have to deal with that all the time". (HEYLIN. Behind The Shades, p. XIX, tradução minha) 
Greenwich Village décadas atrás, e que, a exemplo do que ocorrera em situações semelhantes, a sua presença ofuscaria a dos demais laureados.

O que é a representação, senão a produção de presença de algo que está, no entanto, ausente? No caso de Dylan, a sua mera ausência já teria força suficiente para se afirmar como presença - o que de fato ocorreu, como os extensos comentários a respeito na transmissão da cerimônia evidenciam -, mas ela não se resumiu a isso. Ou seja, não se resumiu a uma ausência absoluta, vazio em que se pudessem projetar livremente uma infinidade de significados arbitrários, afirmando-se ao contrário por dois momentos especiais: a) a apresentação de uma canção sua por Patti Smith; ${ }^{11}$ b) o seu discurso de agradecimento, proferido pela então embaixadora americana na Suécia, Azita Raji. Em ambos os momentos, o que ocorreu foi uma ausência parcial, em que um sujeito cuja figura empírica é demasiado magnética, sai de cena, não sem deixar em seu lugar o sujeito poético. Não restará sem significado que a missão - missão de um outro presente que fala em lugar do eu ausente - tenha sido cumprida por duas mulheres, uma ambivalência a mais que se acumula nesse sistema dinâmico de ausência e presença.

No seu discurso, Dylan afirma como "nunca teria imaginado" que um dia pudesse ganhar um prêmio como o Nobel e fala do que sentiu ao saber da notícia:

[...] precisei de mais do que uns poucos minutos para processar [a notícia]. Comecei a pensar em William Shakespeare. Suponho que ele se imaginasse como um dramaturgo. O pensamento de que ele estivesse escrevendo literatura poderia não passar por sua cabeça. Suas palavras foram escritas para o palco. Para serem faladas, não lidas. Quando ele estava escrevendo Hamlet, tenho certeza de que estava pensando sobre várias coisas diferentes:

\footnotetext{
${ }^{11}$ Ao contrário do que se sugeriu na época, Patti Smith não foi indicada por Dylan para substituí-lo; ela já havia sido convidada pela Academia Sueca antes do anúncio do prêmio. Sua apresentação de "A Hard Rain's A-Gonna Fall” à frente da Orquestra Sinfônica da Suécia mereceria um capítulo à parte. Dominada pela emoção, a cantora teve que interromper a apresentação em duas ocasiões. O fato de uma artista profissional, com mais de 40 anos de carreira, se veja absolutamente tomada por comoção autêntica no exercício de seu ofício, num ramo em que outros ensaiam até seus ataques de tosse, diz muito da integridade de Patti Smith e da importância de Bob Dylan na sua carreira. Ela mesma publicaria um ensaio igualmente comovente sobre a noite do Nobel na revista New Yorker. (Cf. SMITH. How does it feel)
} 


\begin{abstract}
"Quem são os atores certos para esses papéis?", "Como isso deve ser encenado?", "Será mesmo que quero que se passe na Dinamarca?". Aposto que a coisa mais distante da cabeça de Shakespeare era a pergunta "Isso é literatura?"12
\end{abstract}

Um poeta "não se faz somente com a própria geração a que pertencem os seus ossos", ${ }^{13}$ diz Eliot em "Tradição e talento individual", e o faminto explorador da tradição literária e musical que Dylan é não demonstra a menor "angústia da influência" ao se colocar como herdeiro de Shakespeare. Seu exemplo faz pensar ainda nos caminhos tortuosos pelos quais a tradição se estabelece, como se quisesse evidenciar o quanto a aura de solenidade, que atualmente cerca o nome de Shakespeare, não se coaduna com o entertainer que ele era, e que Dylan é. A distinção entre o erudito e o popular, que é o critério calado na maioria das vezes em que se faz a pergunta "o que é literatura?" se altera no decorrer do tempo em movimentos sempre frenéticos, instabilidade sintomática da sua insuficiência para negar o quanto os dois bardos estão próximos.

Ao optar por se deixar representar por suas palavras, por sua arte, por sua ausência fantasmagórica, Dylan abriu espaço para que as atenções se deslocassem da banalidade do seu eu empírico - sua roupa, sua falta de jeito para solenidades, sua provável falta de sorrisos, seu entusiasmo talvez insuficiente ao cumprimentar a Rainha Silvia, sua atenção (ou não) com os outros laureados - para a feição muito mais produtiva do seu eu simbólico: o trovador que fala numa das mais emblemáticas canções do século XX, a consciência crítica por trás do instinto criativo, o renovador da tradição que se afirma também como seu portador. A despeito da pompa e circunstância da ocasião, aquele ainda não seria o capítulo final, e a consciência crítica ainda recalcitrante ressurgiria hipertrofiada, meses mais tarde.

\footnotetext{
12 "it took me more than a few minutes to properly process it. I began to think about William Shakespeare [...] I would reckon he thought of himself as a dramatist. The thought that he was writing literature couldn't have entered his head. His words were written for the stage. Meant to be spoken not read. When he was writing Hamlet, I'm sure he was thinking about a lot of different things: 'Who're the right actors for these roles?' 'How should this be staged?' 'Do I really want to set this in Denmark?' [...] I would bet that the farthest thing from Shakespeare's mind was the question 'Is this literature?"”. (DYLAN. Nobel Lecture, tradução minha)

${ }^{13}$ ELIOT. Ensaios, p. 39.
} 


\section{Heterogeneidade}

Distendido por Dylan até seu limite máximo, o adiamento em ocupar plenamente o lugar de "vencedor do Nobel de Literatura" encontraria o seu termo em 5 de junho de 2017, apenas uma semana antes do prazo final estabelecido pela Academia para que se cumprisse integralmente o rito de entrega do prêmio. Numa reafirmação do seu apreço tanto pela láurea concedida quanto pela própria privacidade, Dylan recebera o diploma e a medalha num encontro secreto com o comitê da Academia em Estocolmo, em abril, mas para ter direito ao prêmio em dinheiro faltava a contrapartida regularmente exigida: uma conferência, ou considerada a natureza do trabalho do laureado, uma apresentação musical a ser realizada até seis meses após a cerimônia de 10 de dezembro. Dylan optou pela forma convencional, entregando uma gravação de 27 minutos em que discorre com prosódia inconfundível sobre a própria trajetória, Buddy Holly e Homero, Nada de novo no Front e Moby Dick, segundo ele mesmo "numa tentativa de refletir como minhas canções estariam relacionadas com a literatura". ${ }^{14}$ Sobre o romance de Melville:

Tudo está misturado. Todos os mitos: a bíblia judaico-cristã, mitos hindus, lendas britânicas, São Jorge, Perseu, Hércules - são todos baleeiros. Mitologia grega, o negócio sangrento de cortar uma baleia. Muitos fatos nesse livro, conhecimento geográfico, óleo de baleia - bom para as coronárias da realeza - famílias nobres da indústria baleeira. O óleo de baleia é usado para ungir os reis. História da baleia, frenologia, filosofia, teorias pseudo-científicas, justificativas para discriminação - tudo jogado lá dentro e nada muito racional. Erudito, popular, a busca da ilusão, a busca da morte, a grande baleia branca, branca como um urso polar, branca como os homens brancos, o imperador, a nêmesis, a encarnação do demônio. O capitão demente que perdeu sua perna anos atrás tentando atacar Moby com uma faca. ${ }^{15}$

\footnotetext{
14 "How my songs related to literature". (DYLAN. Nobel Lecture, tradução minha) 15 "Everything is mixed in. All the myths: the Judeo Christian bible, Hindu myths, British legends, Saint George, Perseus, Hercules - they're all whalers. Greek mythology, the gory business of cutting up a whale. Lots of facts in this book, geographical knowledge, whale oil - good for coronation of royalty - noble families in the whaling industry. Whale oil is used to anoint the kings. History of the whale, phrenology, classical philosophy, pseudo-scientific theories, justification for discrimination - everything
} 
O trecho é sobre Moby Dick, mas trocados alguns substantivos poderia ser sobre a Recherche, de Proust, ou Grande Sertão: Veredas. A maneira como a mistura e a forma da mistura são sublinhadas é surpreendentemente precisa em evocar uma característica ao mesmo tempo específica e abrangente da forma do romance. Há algo da sátira menipeia que Frye identifica como um dos subgêneros da narrativa moderna, aquela "visão do mundo nos termos de uma simples configuração intelectual", ${ }^{16}$ em que a "erudição exaustiva" comparece como matéria prima a ser remodelada pela imaginação do escritor, ao invés de submetida a um apostolado pedagógico. ${ }^{17}$ Não por acaso, Moby Dick é um livro que, como as canções de Dylan, não se deixa confinar com facilidade em categorias como "alta literatura" ou cultura popular; o humor e a reflexão existencial, o enredo movimentado e uma verdadeira teoria da narrativa caminham lado a lado, atraindo um largo espectro de leitores.

É curioso que nenhuma das três obras escolhidas por Dylan para refletir sobre o modo como suas canções se relacionam à literatura pertença ao gênero lírico, cujo parentesco com a canção parece mais óbvio. A própria palavra inglesa lyrics nomeia não apenas o que genericamente entendemos como poesia na modernidade (poesia lírica em sua maioria), mas também a letra da canção. Podemos ver aí um desejo de fugir ao lugar comum, voltando-se para o que está menos evidente, atitude que de certa maneira caracteriza o seu trabalho como compositor. De modo análogo, quando escolhe tratar da mistura heterogênea de discursos que dá forma a Moby Dick, Dylan está enfatizando um elemento formal que é mais específico e de muito maior relevância teórica (e ao mesmo tempo menos evidente) do que aqueles que vinham sendo levantados pela mídia e pela crítica desde a concessão do prêmio. Nesse deslocamento há algo do ofício do crítico, que deve estar sempre atento às armadilhas do senso comum.

\footnotetext{
thrown in and none of it hardly rational. Highbrow, lowbrow, chasing illusion, chasing death, the great white whale, white as polar bear, white as a white man, the emperor, the nemesis, the embodiment of evil. The demented captain who actually lost his leg years ago trying to attack Moby with a knife". (DYLAN. Nobel Lecture, tradução minha) ${ }^{16}$ FRYE. Anatomia da crítica, p, 304.

${ }^{17}$ Para mais sobre a "sátira menipeia", inclusive com exemplos retirados de Moby Dick, cf. FRYE. Anatomia da crítica, p. 303-307.
} 
A estratégia de eleger um elemento formal como tema de aproximação entre suas canções e a literatura, ao invés de uma eventual temática comum a elas, é em si mesma a afirmação de uma consciência crítica. Enquanto nos lances anteriores essa discussão se encenava de modo indireto, no último ato de sua resposta, a consciência crítica toma as rédeas, e os problemas formais implicados ganham nitidez. Não seria sem propósito imaginar um percurso progressivo da mínima sugestão à máxima contundência, dada finalmente na reflexão - agora direta - do artista sobre a natureza do objeto literário. Esta já se iniciara no discurso de agradecimento, mas com certo teor de negatividade: "eu não tenho tempo para pensar se minhas canções são literatura", dissera Dylan, mas eis que passados alguns meses a ocasião se apresenta.

Aqui já se pode afirmar um objetivo implícito desde o início deste artigo: observar uma "teoria dos gêneros" que se enuncia por uma voz que, não sendo a do especialista, é ao mesmo tempo habilíssima em manejar os seus instrumentos, projetando na própria linguagem que utiliza os temas que lhe interessa tratar. A maneira como Dylan enfrenta a discussão sobre os gêneros que se lhe colocara é essencialmente formal (e nesse sentido oposta à perspectiva dominante nos estudos da cultura pop, que privilegia critérios como o suporte em que a obra se oferece, o público a que ela se dirige, ou as implicações sócio-políticas do perfil do autor). Ao invés de simplesmente discutir uma taxonomia, ele se embrenha na mistura formal, indo além da mera catalogação cujo objetivo é apenas definir se canção é ou não é literatura.

Essa voz refinada, consciente do poder da linguagem, afirma a presença do grão literário não apenas nas suas canções, mas na vida em sua dimensão não necessariamente "artística". O cruzamento de fronteiras se dá não apenas entre as diversas formas de criação artística; a própria fronteira que separa o discurso enunciado no âmbito da arte daqueles que enunciamos fora dela é apagada. Na linguagem de dia de semana, na entrevista, no discurso de agradecimento, na conversa cotidiana, na própria encenação do nosso modo de ser particular, que é também linguagem, há espaço para recursos sofisticados como a elipse, a ironia, a representação e a heterogeneidade discursiva.

O caminho oblíquo escolhido aqui, de passar ao largo da discussão quanto ao estatuto da canção, é uma tentativa de focalizar a fala do artista fora do objeto artístico estrito; um discurso que se pronuncia do lado de fora das fronteiras do poema, da canção, do lírico, épico ou dramático, 
mas que ainda assim reivindica para si a condição de literatura, pois incorpora à vida aquela integração (que não precisa ser harmônica) entre forma e conteúdo tão essencial ao objeto literário.

A forma do romance tem muito a revelar sobre as canções de Dylan, e ouso dizer, sobre a própria poesia moderna. ${ }^{18 ~ " E u ~ q u e r i a ~ e s c r e v e r ~}$ canções diferentes de qualquer coisa que qualquer um já ouvira antes", ${ }^{19}$ afirma Dylan, e a polifonia do romance, o choque de discursos heteróclitos utilizados como matéria prima para a maquinaria da linguagem, como fizera Melville em Moby Dick, é o processo até então inédito no âmbito da música popular que as suas maiores canções colocam em ação. "Nada muito racional", como diz o cantor. A magia acontece é no encontro dos olhos com a letra, do ouvido com a voz, momento em que o leitor/ ouvinte liberta a narrativa e o poema ou a canção da sua multiplicidade significativa até então apenas latente. O compositor e o escritor também são, em primeiro lugar, ouvintes e leitores, e não é à toa que se diz do bom músico que tem "bom ouvido" e não "boas mãos"; o grande escritor é também aquele que tem "bons olhos", para ler no mundo e na vida o que os outros não conseguem ler.

Dylan é, antes de tudo, um colecionador. Importantíssimo notar, um colecionador assistemático, (que não se orienta pela totalização, mas que sabe escolher) congregando nas suas canções materiais díspares como a Bíblia, Shakespeare, poesia moderna, a tradição mais antiga do cancioneiro popular e a cacofonia contemporânea, misturados sem hierarquia por uma consciência criadora dotada de grande maestria no uso da linguagem. Peças clássicas como "Desolation Row" e "Like a Rolling Stone", joias menos conhecidas como "Brownsville Girl" e "Dignity", e canções recentes já elevadas a cânone da tradição norte-americana como "Mississippi”" são feitas dessa matéria heterogênea. Mas penetrar nessas canções já seria outro assunto.

${ }^{18}$ Pode-se negar que uma definição para o romance tão lapidar como a de Lukács - "mundo contingente e indivíduo problemático são realidades mutuamente condicionantes" (LUKÁCS. A teoria do romance, p. 79) - se encontra traduzida com proficiência em grandes autores líricos do século XX como Eliot, Drummond, Seamus Heaney e... Bob Dylan?

19 "I wanted to write songs unlike anything anybody even heard". (DYLAN. Nobel Lecture, tradução minha) 


\section{Referências}

DYLAN, Bob. Banquet Speech. Stockholm: The Nobel Foundation, 2016. Disponível em: < https://www.nobelprize.org/nobel_prizes/ literature/laureates/2016/dylan-speech_en.html>. Acesso em: $15 \mathrm{dez}$. 2017.

DYLAN, Bob. Nobel Lecture. Stockholm: The Nobel Foundation, 2017. Disponível em: <https://www.nobelprize.org/nobel_prizes/literature/ laureates/2016/dylan-lecture.html>. Acesso em: 3 dez. 2017.

ELIOT, T.S. Ensaios. Tradução de Ivan Junqueira. São Paulo: Art Editora, 1989.

FRYE, Northrop. Anatomia da crítica. Tradução de Péricles Eugênio da Silva Ramos. São Paulo: Cultrix, 1973.

GUNDERSEN, Edna. World exclusive: Bob Dylan - I'll be at the Nobel Prize ceremony... if I can. The Telegraph, 29 oct. 2016. Disponível em: $<$ http://www.telegraph.co.uk/men/the-filter/world-exclusive-bob-dylan--ill-be-at-the-nobel-prize-ceremony-i/>. Acesso em: 15 nov. 2017.

HEYLIN, Clinton. Behind the Shades: The 20th anniversary edition. London: Faber \& Faber, 2011.

LUKACS, 2000. A teoria do romance. São Paulo: Duas cidades: Editora 34, 2000.

PONTIKIS, Annika. Newsroom for the Nobel Foundation. Stockholm: The Nobel Foundation, 2016. Disponível em: $<$ https://www.nobelprize. org/press/\#/publication/581>. Acesso em: 3 dez. 2017.

SAFATLE, Vladimir. Cinismo e falência da crítica. São Paulo: Boitempo, 2008.

SARTRE, Jean Paul. Carta à Academia Sueca. Última hora, 23 out. 1964. Disponível em: $<$ http://homoliteratus.com/carta-de-jean-paul-sartrerecusando-o-premio-nobel-de-literatura/>. Acesso em: 5 dez. 2017.

SMITH, Patti. How does it feel. New Yorker, 14 dec. 2016. Disponível em: $<$ https://www.newyorker.com/culture/cultural-comment/patti-smith-onsinging-at-bob-dylans-nobel-prize-ceremony>. Acesso em: 15 dez. 2017.

Recebido em: 20 de dezembro de 2017. Aprovado em: 13 de março de 2018. 